\title{
Dengue Epidemic Situation in Bangladesh
}

\author{
Mohiuddin AK* \\ Assistant Professor, Department of Pharmacy, World University of Bangladesh, Dhaka, Bangladesh
}

*Corresponding author: Mohiuddin AK, Assistant Professor, Department of Pharmacy, World University of Bangladesh, Dhaka, Bangladesh, E-mail: trymohi@gmail.com

Received: 08 Sep, 2019 | Accepted: 18 Sep, 2019 | Published: 23 Sep, 2019

Citation: Mohiuddin AK (2019) Dengue Epidemic Situation in Bangladesh. J Clin Case Stu 4(3): dx.doi.org/10.16966/2471-4925.193

Copyright: ๑ 2019 Mohiuddin AK. This is an open-access article distributed under the terms of the Creative Commons Attribution License, which permits unrestricted use, distribution, and reproduction in any medium, provided the original author and source are credited.

\begin{abstract}
Up to 50-100 million infections are now estimated to occur annually in over 100 endemic countries, putting almost half of the world's population at risk. Bangladesh is one of the countries that are affected by dengue viruses. Dengue is a viral infection caused by four types of viruses (DENV-1, DENV-2, DENV-3, DENV-4) belonging to the Flaviviridae family. Mosquitoes are vectors of this arbovirus and breed in areas with standing water, including puddles, water tanks, containers, and old tires. Lack of reliable sanitation and regular garbage collection also contribute to the spread of mosquitoes. The disease has probably been known since the Chinese described it in 420 AD. Outbreaks are increasing although there is no humanto-human transmission only mosquito-to-human viral transmission. The disease is colloquially known by Africans as "kadingapepo" as cramp-like seizure caused by an evil spirit. The Spanish may have changed "dinga" to dengue since it means fastidious or careful in Spanish, which describes the gait of people trying to reduce the pain of walking. With the increasing number of patients, hospitals outside Dhaka are facing huge challenges to cope with the pressure, mostly due to lack of diagnosis chemicals, kits, and other medical support.
\end{abstract}

Keywords: Dengue; Vaccines; Topical essential oils; Mosquito repellents; Neem oil; Permethrin-treated clothing

\section{Introduction}

The proof of the utilization of plants for medicinal purposes dates as far back as 60,000 years ago. As of late, the WHO assessed that $80 \%$ of people depend on natural medications for their healthcare needs. Among 250,000 to 500,000 types of plants that exist on earth, 35000 are utilized worldwide for medicinal purposes, 20000 medicinal plants are accessible in Indian subcontinent, and about 3000 have shown their potential in malignancy, 1200 in diabetes and 2000 in nuisance control programs. Around the world, mosquitoes transmit sickness to about 700 million people [1]. Among them, 390 million were influenced with dengue consistently before 2013 and roughly 3.9 billion people live in dengue-endemic nations. 2.4 million people are tainted with dengue every year in Bangladesh. After chikungunya flare-up between 2008-2017 in Bangladesh, the adrenaline junkie mosquitoes have made a loathsomeness circumstance with dengue fever. More than 50000 infected in August alone [2] and some people around keep saying that almighty is punishing people like he punished Nomrud, the most powerful king of his time, who was defeated by one weak mosquito. Fact is we still lack actual measures.

\section{Literature Review}

The first licensed dengue vaccine, Dengvaxia (Sanofi), received regulatory approval in a number of countries but had some limitations [3]. Costs of two other live-attenuated vaccine candidates, DENvax (Japan) and TV003/TV005 (US) are not within the reach of average people. In Indonesia Dengvaxia costs about US \$207 for the recommended three doses [4]. Some available mosquito repellant creams are hiking 10 times price than actual price, so how much Dengvaxia will hike, if available, we can very well imagine and which mosquito-borne disease will be epidemic next time is uncertain. So, we have to focus on mosquito bite prevention, not dengue or chikungunya. Climate change is a very important factor of Flavivirus (genus type of dengue virus) transmission but not the sole factor [5]. Along with climate change, aberrant use of pesticides and their resistance is also noted in recent dengue affected countries. Most commonly used insecticides in households (Metafluthrin \& D-allethrin), mosquito coils repel mosquito and kerosene fog by city corporation kills larvae and ensures effective adult mosquito eradication for short-term. The use of coil protective stands is necessary to prevent fire incident and accidental touch. Mosquito proof nets are applied in many households and air blower in a few supermarket entrances are not enough for disease prevention and mostly unaffordable/unsuitable for general use. Full-sleeve cloths can reduce mosquito bite incidents but rarely ensures prevention from mosquito-transmitted viral diseases. Permethrin/malathion-treated military clothing has shown to be effective in significantly reducing mosquito bites in the covered regions [6]. There is also an abundance of fixed or moveable electric devices (for example: mosquito bats or electric coils) and wearable devices that are available, including bracelets, sonic devices, clothing, and skin patches. Their accessibility, availability, affordability and practical uses varied among different people. 
There are a few common misconceptions like garlic and coconut oil as effective repellents. Topical applications of garlic oil and garlic consumption with Vitamin B supplements have not been able to repel mosquitoes. But garlic essential oil can be an effective pesticide against mosquitoes when microencapsulated and used in an attractive toxic sugar baits system [7]. Many fake herbal or homeopathic liver tonics are available in the market claiming improved platelet count after use. A common tale told by people "burning one mosquito coil in a closed room amounts to smoking roughly 100 cigarettes" has little scientific value. It's true that a burning coil has health effect but it's better than having deadly mosquito bites. The key message should be to avoid prolonged exposure, especially in enclosed spaces. Some smokers give it a reason that smoking prevents mosquito bites. A few smokers give it a reason that smoking counteracts mosquito nibbles. People with the large body surface, pregnant women, infants and youths (age underneath 20) generally draw in mosquitoes because of their inclination to emit more carbon dioxide [8]. Likewise, alcoholic blood and blood group "O" attracts mosquitoes $[9,10]$. The effect of smoking on platelet count is still controversial. Aedes aegypti mosquitoes (the main vector of dengue) are known to bite during day-time hours [11]. Thus, the use of mosquito-nets should not be just limited to night-time during but also encouraged for day-time use too. Parks and lakes are places where people get mosquito bites frequently. It is better walking/ running there and leaving the place soon after finishing walk avoiding idle sitting back and gossip. Since platelet count is compromised, conventional painkillers other than paracetamol should be avoided strictly because of their negative impression on platelet count [12].

\section{Present Dengue Epidemic Situation}

Around 3500 dengue patients are taking service of public/private hospitals around the country with more than 500-700 patients taking admission every day [13]. Between August 12-18, at least 12,000 dengue patients were admitted to different hospitals across the country (we are still going through this endemic situation) and 6,866 of them outside Dhaka [14]. The situation was even worse in between July-August, 2019. Hospitals were struggling with the patients. The numbers of dengue patients above 18 years of age were 10,528 infected till July 27, 2019 [15] and more. Around 51,000 dengue patients hospitalized in August only [16]. 1,712 more people were hospitalized with the mosquito-borne virus on $31^{\text {st }}$ July 2019 . Of them, 1,150 dengue cases were reported in the capital alone [17]. However, public awareness is the best initiative against dengue. Household wastes are the larval habitats of dengue vector. City Corporation has taken initiatives to penalize households and offices with poor waste management and arranged kerosene fog spray once in a week but seem a half-hearted shot.

\section{Conclusion}

If we go back to plant-derived mosquito repellents, we will have a few options for topical use. Topical application of neem, lemongrass, peppermint, and eucalyptus oil have equivalent efficacy of DEET (banned in Denmark, EU, US, UAE, Canada but available in Bangladesh) but relatively safe in use [18-23]. Conventional topical cream diethyl benzamide (ODOMOS/TRIG) also shows significant dermal and neurotoxicity [24]. Their use can be limited to feet and ankles $[25,26]$. Burning neem leaves provided nearly $80 \%$ protection against mosquitoes for 2 hours [18]. However, to get similar efficacy like eucalyptus oil, more than 20 times higher concentration of neem oil was required [27]. Neem infused water [28], papaya leaf juice [29-35], Gulancha (Tinospora cordifolia) and Tit Begun (Solanum xanthocarpum) shown to increase both blood platelets and WBC count, two of which are the worst side effects of dengue fever [36]. However, none of the above mentioned have been reported as safe in infant and pregnant women. Ripe papaya during pregnancy may not pose any significant danger. Drinking papaya juice with a few lemons drops in it may also work [37]. Folate and iron-rich foods, Vitamins B12, C, D, and K improve platelet count [38].

\section{References}

1. Ryan SJ, Carlson CJ, Mordecai EA, Johnson LR (2019) Global Expansion and Redistribution of Aedes-Borne Virus Transmission Risk with Climate Change. PLoS Negl Trop Dis 13: e0007213.

2. Alam H (2019) Dengue Patients: August Sees More Than 19-yr Total 50,974 Cases Recorded in 30 Days. The Daily Star.

3. Prompetchara E, Ketloy C, Thomas SJ, Ruxrungtham K (2019) Dengue Vaccine: Global Development Update. Asian Pac J Allergy Immunol.

4. TEMPO.CO (2016) Dengue Fever Vaccine Available in Indonesia. Sci \& Tech.

5. Bharati M, Saha D (2018) Multiple Insecticide Resistance Mechanisms in Primary Dengue Vector, Aedes aegypti (Linn.) from Dengue Endemic Districts of Sub-Himalayan West Bengal, India. Plos One 13: e0203207.

6. Achee NL, Grieco JP, Vatandoost H, Seixas G, Pinto J, et al. (2019) Correction: Alternative Strategies for Mosquito-Borne Arbovirus Control. PLoS Negl Trop Dis 13: e0007275.

7. Muturi EJ, Ramirez JL, Zilkowski B, Flor-Weiler LB, Rooney AP (2018) Ovicidal and Larvicidal Effects of Garlic and Asafoetida Essential Oils Against West Nile Virus Vectors. J Insect Sci 18: 1-6.

8. Heubeck E (2012) Are You a Mosquito Magnet? WebMD, Allergies.

9. Shirai O, Tsuda T, Kitagawa S, Naitoh K, Seki T, et al. (2002) Alcohol Ingestion Stimulates Mosquito Attraction. J Am Mosq Control Assoc 18: 91-96.

10. Ewald DR, Sumner SC (2016) Blood Type Biochemistry and Human Disease. Wiley Interdiscip Rev Syst Biol Med 8: 517-535.

11. Ndenga BA, Mutuku FM, Ngugi HN, Mbakaya JO, Aswani P, et al. (2017) Characteristics of Aedes aegypti Adult Mosquitoes in Rural and Urban Areas of Western and Coastal Kenya. Plos One 12: e0189971.

12. Wong RSY (2019) Role of Nonsteroidal Anti-Inflammatory Drugs (NSAIDs) in Cancer Prevention and Cancer Promotion. Adv Pharmacol Sci 2019: 3418975.

13. Tribune Desk (2019) DGHS: 607 More Hospitalized for Dengue in 24hrs. DhakaTribune.

14. Alam H (2019) Dengue Situation: Now Alarming Also Outside the Capital. The Daily Star.

15. Alam H, Mollah S (2019) Hospitals Struggling. The Daily Star.

16. Tribune Desk (2019) Nearly 51,000 Dengue Patients Hospitalized in August Only. DhakaTribune.

17. Independent Online/UNB (2019) Dengue Cases Still on the Rise. The independent.

18. Maia MF, Moore SJ (2011) Plant-based Insect Repellents: A Review of their Efficacy, Development and Testing. Malar J 10: S11.

19. Lee MY (2018) Essential Oils as Repellents Against Arthropods. BioMed Res Int 2018: 1-9.

20. Reichert W, Ejercito J, Guda, T, Dong X, Wu Q, et al. (2019) Repellency Assessment of Nepeta cataria Essential Oils and Isolated Nepetalactones on Aedes aegypti. Scientific reports 9: 1524. 
21. Abiy E, Gebre-Michael T, Balkew M, Medhin G (2015) Repellent Efficacy of DEET, MyggA, Neem (Azedirachta indica) Oil and Chinaberry (Melia azedarach) Oil Against Anopheles arabiensis, the Principal Malaria Vector in Ethiopia. Malar J 14: 187.

22. Muema JM, Bargul JL, Njeru SN, Onyango JO, Imbahale SS (2017) Prospects for Malaria Control Through Manipulation of Mosquito Larval Habitats and Olfactory-Mediated Behavioural Responses Using PlantDerived Compounds. Parasit Vectors 10: 184

23. Kimutai A, Ngeiywa M, Mulaa M, Njagi PG, Ingonga J, et al. (2017) Repellent Effects of the Essential Oils of Cymbopogon citratus and Tagetes minuta on the Sandfly, Phlebotomus duboscqi. BMC Res Notes 10: 98.

24. Swale DR, Sun B, Tong F, Bloomquist JR (2014) Neurotoxicity and Mode of Action of N, N-diethyl-meta-toluamide (DEET). PloS One 9: e103713.

25. Chen-Hussey V, Behrens R, Logan JG (2014) Assessment of Methods Used to Determine the Safety of the Topical Insect Repellent N,N diethyl-m-toluamide (DEET). Parasit Vectors 7: 173.

26. Msangi S, Kweka E, Mahande A (2018) Repellent Activity of TRIG (N-N Diethyl Benzamide) Against Man-Biting Mosquitoes. J Trop Med 2018: 1-5.

27. Kaura T, Mewara A, Zaman K, Sharma A, Agrawal SK, et al. (2019) Utilizing Larvicidal and Pupicidal Efficacy of Eucalyptus and Neem Oil Against Aedes mosquito: An Approach for Mosquito Control. Trop Parasitol 9: 12-17.

28. Udeinya IJ, Mbah AU, Chijioke CP, Shu EN (2004) An Antimalarial Extract from Neem Leaves is Antiretroviral. Trans R Soc Trop Med Hyg 98: 435437.

29. Dharmarathna SL, Wickramasinghe $S$, Waduge RN, Rajapakse RP, Kularatne SA (2013) Does Carica papaya Leaf-Extract Increase the Platelet Count? An Experimental Study in a Murine Model. Asian Pac Trop Biomed 3: 720-724.
30. Gadhwal AK, Ankit BS, Chahar C, Tantia P, Sirohi P, et al. (2016) Effect of Carica papaya Leaf Extract Capsule on Platelet Count in Patients of Dengue Fever with Thrombocytopenia. J Assoc Physicians India 64: $22-26$

31. Subenthiran S, Choon TC, Cheong KC, Thayan R, Teck MB, et al. (2013) Carica papaya Leaves Juice Significantly Accelerates the Rate of Increase in Platelet Count among Patients with Dengue Fever and Dengue Haemorrhagic Fever. Evid Based Complement Alternat Med 2013: 1-7.

32. Charan J, Saxena D, Goyal J, Yasobant S (2016) Efficacy and Safety of Carica Papaya Leaf Extract in the Dengue: A Systematic Review and Meta-Analysis. Int J Appl Basic Med Res 6: 249-254.

33. Pandita A, Mishra N, Gupta G, Singh R (2019) Use of Papaya Leaf Extract in Neonatal Thrombocytopenia. Clin Case Rep 7: 497-499.

34. Ahmad N, Fazal H, Ayaz M, Abbasi BH, Mohammad I, et al. (2011) Dengue Fever Treatment with Carica papaya Leaves Extracts. Asian Pac J Trop Biomed 1: 330-333.

35. Srikanth BK, Reddy L, Biradar S, Shamanna M, Mariguddi DD, et al. (2019) An Open-Label, Randomized Prospective Study to Evaluate the Efficacy and Safety of Carica papaya Leaf Extract for Thrombocytopenia Associated with Dengue Fever in Pediatric Subjects. Pediatric Health Med Ther 10: 5-11.

36. Lugun O, Bhoi S, Kujur P, Kumar DV, Surin WR (2018) Evaluation of Antithrombotic Activities of Solanum xanthocarpum and Tinospora cordifolia. Pharmacognosy Res 10: 98-103.

37. Adebiyi A, Adaikan PG, Prasad RN (2002) Papaya (Carica papaya) Consumption is Unsafe in Pregnancy: Fact or Fable? Scientific Evaluation of a Common Belief in Some Parts of Asia Using a Rat Model. Br J Nutr 88: 199-203.

38. Leonard J (2018) How Can I Increase My Platelet Count Naturally? Medical News Today. 